\title{
openheart Long-term survival in patients who had CABG with or without prior coronary artery stenting
}

\author{
Pratik Rai (D) , Rebecca Taylor (D), Mohamad Nidal Bittar
}

To cite: Rai P, Taylor R, Bittar MN. Long-term survival in patients who had CABG with or without prior coronary artery stenting. Open Heart 2020;7:e001160. doi:10.1136/ openhrt-2019-001160

Received 27 August 2019 Revised 29 April 2020 Accepted 1 June 2020
D) Check for updates

C) Author(s) (or their employer(s)) 2020. Re-use permitted under CC BY-NC. No commercial re-use. See rights and permissions. Published by BMJ.

Department of Cardiothoracic Surgery, Lancanshire Cardiac Center, Blackpool Victoria Hospital, Blackpool, UK

Correspondence to Mr Pratik Rai; blue.rai@hotmail. co.uk

\section{ABSTRACT}

Objective To conduct a large-scale, single-centre retrospective cohort study to understand the impact of prior percutaneous coronary intervention $(\mathrm{PCl})$ on longterm survival of patients who then undergo coronary artery bypass graft (CABG).

Methods Between 1999 and 2017, a total of 11332 patients underwent CABG at a hospital in the UK. The patients were stratified into those who received $\mathrm{PCI}$ ( $n=1090)$ or no $\mathrm{PCl}(\mathrm{n}=10242)$ prior to CABG. A total of 1058 patients from each group were matched using propensity score matching. Kaplan-Meier estimates were used to assess risk-adjusted survival in patients with prior $\mathrm{PCl}$. Cox proportional hazards ( $\mathrm{CoxPH}$ ) model was then used to assess the effect of prior $\mathrm{PCl}$ and other variables in patients undergoing CABG.

Results The immediate postoperative outcome showed no difference in number of grafts per patients, blood transfusion, hospital stay or 30 days mortality between the groups. There was no significant difference in 5 years (90.8\% vs 87.9$), 10$-year ( $76.5 \%$ vs $74.6 \%$ ) and 15 -year $(64.4 \%$ vs $64.7 \%)$ survival between the non-PCl versus $\mathrm{PCl}$ groups. The Cox proportional hazards model further supports the null hypothesis as the $\mathrm{PCl}$ variable was found to be non-significant ( $\mathrm{CoxPH}=1.03, \mathrm{p}=0.75, \mathrm{Cl}=0.87-1.22$ ) implying there was no difference in hazard of death for CABG patients with or without previous PCI. However, the model did yield information on the covariates that do affect the hazard of death

Conclusion There is no difference in 5-year, 10-year and 15-year survival between patients undergoing CABG with or without prior $\mathrm{PCl}$. However, certain patient, preoperative and intraoperative risk factors were identified with high hazard of death which needs to be investigated further.

\section{INTRODUCTION}

An estimated $10 \%$ of the population in the UK presently live with cardiovascular disease of which 66000 deaths are attributed to coronary heart disease (CHD). ${ }^{1}$ When medical management is unsatisfactory in alleviating the ischaemic symptoms, surgical options are considered. Coronary artery bypass graft (CABG) has remained the gold-standard surgical intervention. CABG involves the use of a vascular conduit, commonly the saphenous vein, as a graft. Although it is becoming

\section{Key questions}

What is already known about this subject?

- Percutaneous coronary intervention $(\mathrm{PCl})$ is the intervention of choice for treating most single vesse diseases, however, coronary artery bypass graft (CABG) is superior for patients with complex multivessel disease and diabetes.

- PCl stents have been documented to cause local inflammatory changes, thus, patients with $\mathrm{PCl}$ are at risk of restenosis for which $\mathrm{CABG}$ is often conducted.

- However, there is heterogeneity in current literature about the outcome in patients with prior $\mathrm{PCl}$ that undergo CABG.

What does this study add?

- This single-centre large retrospective cohort study supports the finding that prior $\mathrm{PCl}$ has no impact on 5-year, 10-year and 15-year survival compared with patients without prior $\mathrm{PCl}$

- However, we have discovered certain risk factors that are associated with prior $\mathrm{PCl}$ which requires further investigation.

How might this impact on clinical practice?

- Our finding is reassuring for patients, allowing clinicians to offer CABG as an alternative revascularisation intervention in these cohort of patients.

increasingly common to use arterial conduits such as the internal mammary artery as studies have found that long-term patency rate with arterial grafts are higher. ${ }^{2-4} \mathrm{CABG}$ has been demonstrated to be a highly effective coronary reperfusion strategy for symptom relief of severe angina as well as reducing mortality in this cohort of patients. ${ }^{5}$ However, CABG is not a cure for CHD as it does not stop disease progression and the grafts can calcify with restenosis occurring if lifestyle changes are not made. Furthermore, being highly invasive, CABG also carries risks of myocardial infarction, stroke, arrhythmias and death. ${ }^{6}$

The advent of percutaneous coronary intervention (PCI) has advanced the survival of patients with CHD along with reducing the need for $\mathrm{CABG}^{7}{ }^{7} \mathrm{PCI}$ involves percutaneous access, under local anaesthetic, of the 
femoral, radial or brachial artery to conduct wire guided inflation of an angioplasty balloon. ${ }^{8}$ This compresses the plaque and reopens the vessel, followed by stent deployment to maintain vessel patency. ${ }^{9}$

Unfortunately, the stents are at risk of restenosis through fibrocellular proliferation triggered by the denuded vascular endothelium, leading to a $17 \%-41 \%$ restenosis rate with bare metal stents. In-stent restenosis has been reduced to $<10 \%$ with the introduction of drugeluting stents (DES), ${ }^{10}$ which release drugs to inhibit local cellular proliferation. ${ }^{11}$

There are multiple reasons why prior PCI could lead to worse surgical outcomes. Coronary stenting can induce chronic histopathological changes to the vascular endothelium: multiple imaging and histological studies have reported chronic inflammation with endothelial dysfunction. ${ }^{12}$ This is associated with potential induction of neointimal atherosclerosis inside bare and DES, increasing the risk of in-stent thrombosis or restenosis. ${ }^{13}$ In addition, prior PCI can also increase the technical difficulty of the surgery, including limiting the number of distal anastomoses grafted. ${ }^{14}$ These changes complicate outcomes and the efficacy of repeat revascularisation.

Numerous literatures exist that compare the efficacy of PCI against CABG. Comparison of mortality and morbidity has frequently been drawn between PCI and CABG. PCI is the ideal revascularisation strategy in a single vessel disease although CABG is the superior intervention for multi-vessel disease and diabetics ${ }^{15}{ }^{16}$; longer survival and lower rates of major postoperative cardiovascular complications are observed in this group. ${ }^{1718}$

At present, many patients who had a prior PCI require repeat revascularisation, due to restenosis or progression of coronary disease elsewhere in the coronary circulation, even with DES, are undergoing CABG. ${ }^{19}$ Initial PCI is found to have significantly higher rates of repeat revascularisation $(25.9 \%)$ in comparison to initial CABG $(13.7 \%) .{ }^{20}$ Despite this, numerous studies have reported there is no difference in short to mid-term survival. ${ }^{14}$ However, the adverse effect on long-term survival is not effectively established. There is incongruence in the results found across studies that have been conducted looking at long term follow-up. Some long-term studies found having multiple previous PCI increases major adverse cardiac outcomes after $\mathrm{CABG}^{21}{ }^{22}$ while other studies conclude prior PCI has no significant effect on long term survival post-CABG. ${ }^{23}$

Therefore, a large-scale study needs to be conducted to effectively establish the impact of prior PCI on long-term survival of patients who then undergo CABG.

\section{Aim}

To conduct a large-scale retrospective cohort study to understand the impact of prior PCI on long-term survival of patients who then undergo CABG.

\section{METHODOLOGY}

\section{Data collection}

We conducted a retrospective cohort study consisting of 11332 patients who underwent isolated CABG from 1999 to 2017 at the Blackpool Victoria Hospital. Isolated CABG is defined as having no other simultaneous cardiac intervention performed during the operation.

These patients were categorised into two groups of either prior PCI $(n=1090)$ or no PCI $(n=10242)$. PCI includes balloon angioplasty followed with stent insertion, however, patients who did not require stent insertion following balloon angioplasty were not included in this group. Elective, urgent and emergency cases were included. However, we excluded patients who underwent subsequent CABG due to unsuccessful PCI, patients undergoing PCI and CABG in the same admission and patients who had concurrent cardiac surgery apart from CABG, for example, valve repair or replacement. One further patient with misrecorded dates implying death prior to surgery was also excluded.

Data were extracted from the hospital database validated for National Institute for Cardiovascular Research Outcomes (NICOR) database. ${ }^{24}$ The NICOR database contains clinical data of cardiovascular patients across different hospitals in the UK, including Blackpool Victoria Hospital, and is updated annually. We accessed the NICOR database with the dendrite clinical systems; the information collection system. The NICOR database provides extensive information detailing patient demographics with risk factors, operative and postoperative outcomes including hospital stay, morbidity and mortality. Long-term survival was obtained from National Health Service strategic tracing service and was defined as patients living 15 years after surgery, without further coronary surgical interventions. Information regarding patient demographic are presented in table 1.

\section{Statistical analysis}

The data were analysed by the research statistician based within Blackpool Victoria hospital's Clinical Research Centre and took two main approaches: first, propensity matching was used to create a matched data set of 2116 patients (previous PCI, $\mathrm{n}=1058$ and no previous PCI, $\mathrm{n}=1058$ ) such that preoperative patient characteristics were balanced across the two groups and Kaplan-Meier estimates of long-term survival could then be compared with minimal bias from confounding patient attributes. Matching was performed with MatchIt package in $\mathrm{R}^{25} 26$ using a greedy method based on propensity scores derived from a logistic regression. No calliper was used. The 16 patient covariates included in the matching process, in table 1, which were chosen as they are preoperative risk factors affecting survival in CHD patients. A log-rank test was used to determine the statistical significance of any difference in the Kaplan-Meier estimate of survival between the PCI and non-PCI groups.

Second, to make most efficient use of the full available data ( $\mathrm{n}=11332$ ), a Cox Proportional Hazards model was 


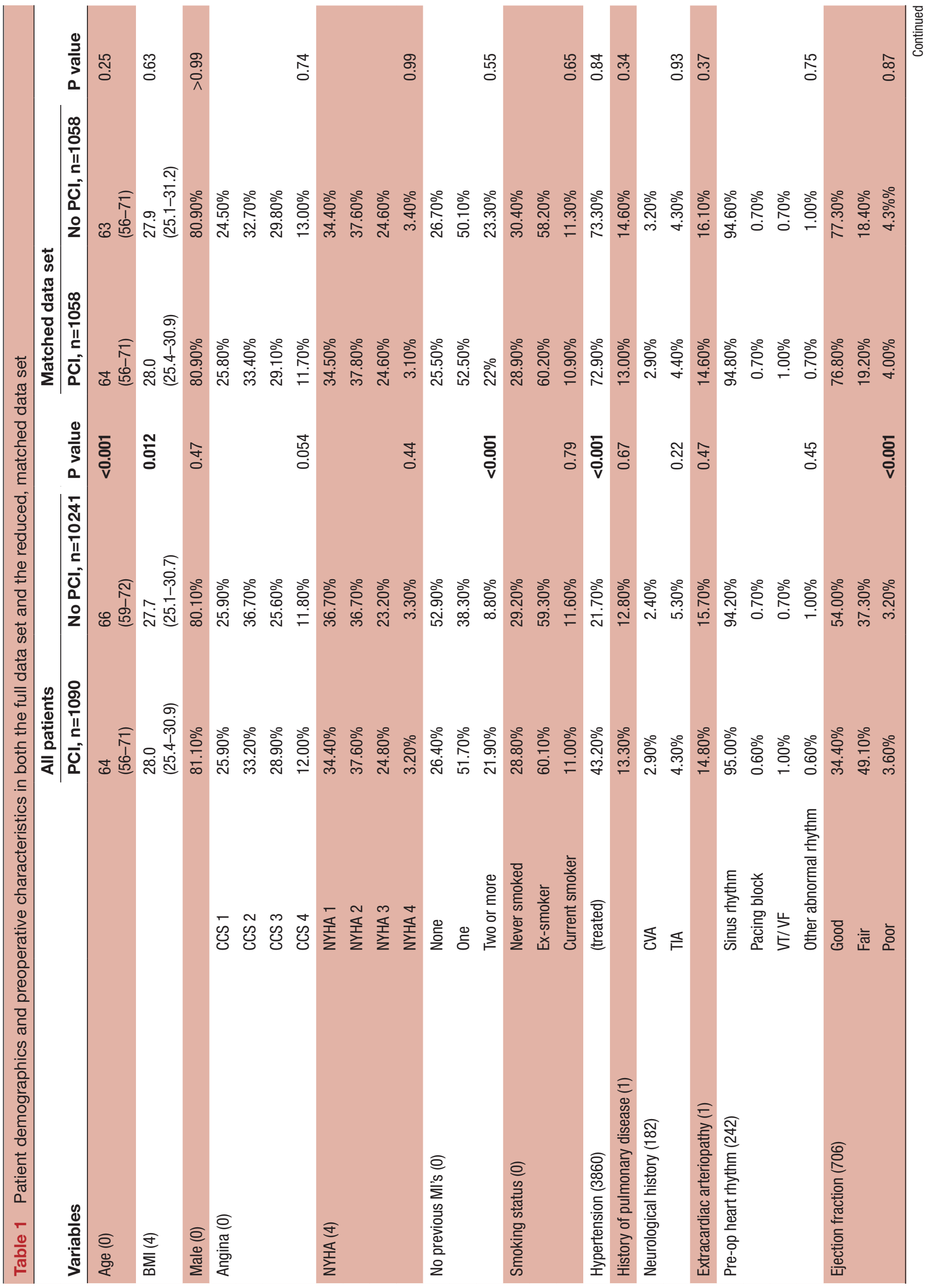




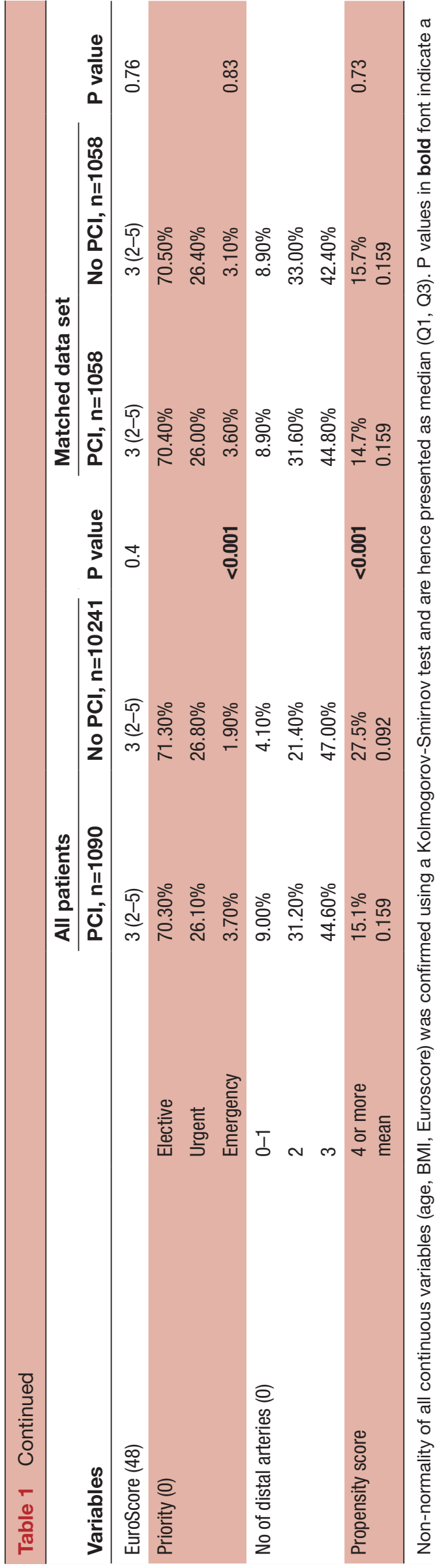

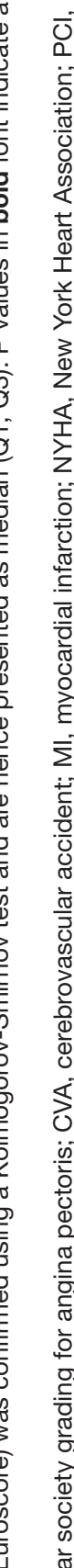

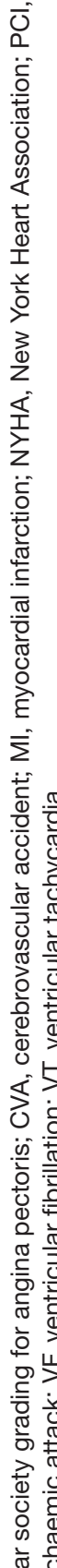

created in order to quantify the effects of a previous PCI, and other preoperative, intraoperative and postoperative variables, on the hazard of death for CABG patients. Stepwise regression was used to determine variables with a statistically significant $(\mathrm{p}<0.05)$ effect on the hazard, while retaining the PCI/non-PCI indicator throughout. Summary data in the form of simple percentage survival rates were also calculated for both the matched data set and the full data set and compared using a $\chi^{2}$ test.

\section{RESULTS \\ Patient demographics and risk factors}

Patient demographics including risk factors are presented in table 1. Non-PCI cohort appeared to be younger, male dominant $(80 \%)$ and more symptomatic (grade 4 CCS score for angina and dyspnoea NYHA), exhibiting more comorbidities. PCI cohort appeared to have significantly greater number of previous MI but better ejection fraction in comparison to the non-PCI cohort. Greater number of patients in the prior PCI group were classed as emergency. Body mass index and Euroscore were similar in both groups.

Following propensity matching, we have identified 1058 patients from each cohort whose preoperative characteristics match sufficiently to give a similar propensity score: the mean distance (probability of prior PCI) was 0.159 in both groups, compared with 0.159 in the PCI group and 0.092 in the non-PCI group before matching (see table 1 and figure 1). The immediate outcomes did not differ in blood loss, chest infection, stroke and in-hospital mortality (1.4\% vs $1.5 \%$ ) between the two matched groups (Table 2). There was minimal variation in the surgical priority between PCI and non-PCI. Up to six distal arteries were grafted in both cohorts.

\section{Survival}

There was no difference in 5 year $(90.8 \%$ vs 87.9$)$, 10 year (76.5\% vs $74.6 \%)$ 15year (64.4\% vs $64.7 \%)$ survival between the non-PCI vs PCI group (table 3). $\chi^{2}$ tests of homogeneity (for categorical variables) or Mann-Whitney tests (for non-normal continuous variables) revealed that none of these differences are statistically significant. Additionally, long-term survival does not reveal any difference between the groups $(64.7 \%$ vs $64.4 \%)$. This is further supported by the Kaplan-Meier survival curve presented on figure 2. The log-rank test of the null hypothesis that survival in the two groups is the same, giving $p=0.9$. This implies strongly that there is no evidence of a difference between the two groups.

Approach 1: propensity matching and Kaplan-Meier estimates A total of 1058 of the possible 1080 PCI patients were matched to 1058 non-PCI patients from the full database using propensity score matching. The balance of propensity scores, shown in figure 1 , is visibly improved after matching (matched group propensity scores shown in the bar charts; 'treated' denotes the previous PCI group). 
Raw Treated

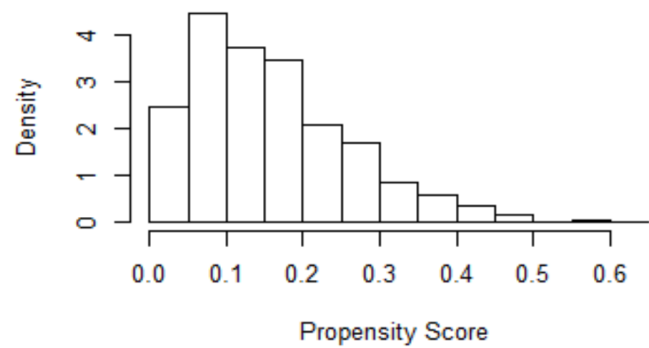

Raw Control

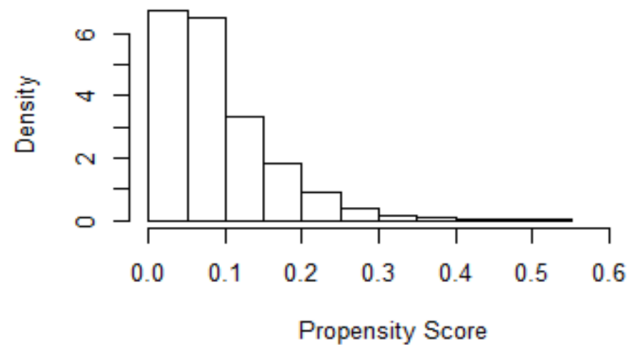

Matched Treated

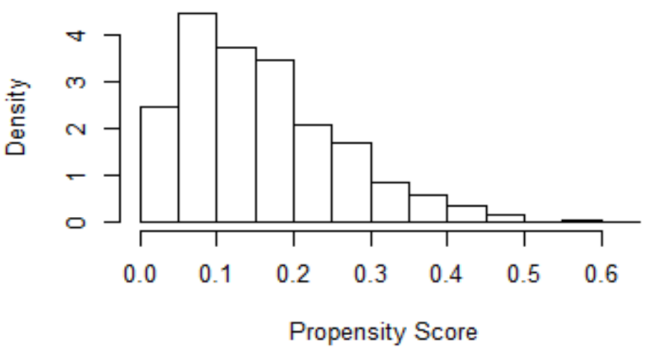

Matched Control

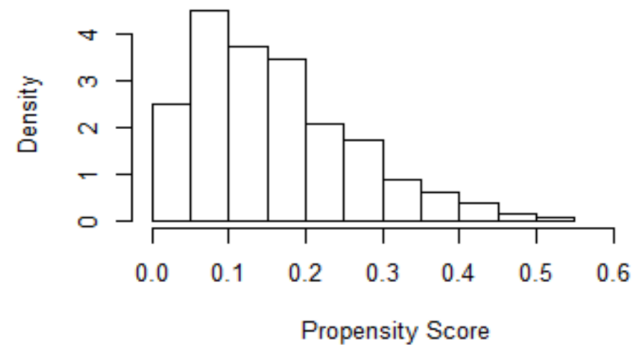

Figure 1 Histograms of the distributions of propensity scores, before matching (left-hand two) and after matching (right-hand two). 'Treated' indicates a prior PCl, 'control' had no prior PCl. We see the two right-hand histograms are satisfactorily similar and have mitigated the differences observed in the full data set, as shown by the two left-hand histograms. PCl, percutaneous coronary intervention.

The Cox proportional hazards model further supports the null hypothesis because the PCI variable was found to be non-significant ( $\mathrm{HR} 1.058, \mathrm{p}=0.59$ ), even after considering all the available $11000+$ patients in the analysis, implying there was no difference in hazard of death for CABG patients with or without previous PCI. Additionally, we also conducted adjusted survival curves using from the Cox proportional hazards model which mirrors the results of Kaplan-Mier Estimates of no difference in survival between PCI versus non-PCI cohort (figure 3). However, the Cox proportional hazards model did yield information on the covariates that do affect the hazard of death. The variables significantly associated with hazard of death are listed in table 4 .

\section{DISCUSSION}

\section{Rise in efficacy of PCI}

PCI is thought to be limited mainly to single vessel disease whereas CABG provided better outcomes in complex multivessel CAD. However, since the advancements of DES, it is increasingly common for PCI to be used for multivessel disease with low CAD complexity. ${ }^{27} 28$ The Synergy Between PCI With TAXUS and Cardiac Surgery (SYNTAX) II trial concluded an enhancement in the efficacy of new generation PCI compared with those in SYNTAX I, demonstrated by reduction in major adverse cardiac and cerebrovascular events: SYNTAX $1110.6 \%$ vs SYNTAX I $17.4 \%$; $\mathrm{p}=6 \times 10^{-3}$ and the need for revascularisation. ${ }^{29}$ Nevertheless, CABG remains superior to PCI for complex multivessel disease as well as overall reduction in need for repeat revascularisation. ${ }^{19}{ }^{30}$ Even with DES, the incidence of repeat revascularisation at 1 year is $12 \%{ }^{31}$

\section{Survival outcomes in patients with and without prior PCI}

Contrasting our results, some studies have reported opposing findings of poor postoperative outcomes in patients with prior PCI, with higher rates of major complication, length of stay and readmission rates. 223233 However, at present, there is conflicting evidence in the literature concerning the impact of survival in this cohort of patients: short-term and mid-term mortality reported by some articles are significantly higher in patients with prior PCI, one article reporting 5-year discrepancy in mortality rate among patients with and without prior PCI (PCI $=14 \%$ vs non-PCI $=9 \%, \mathrm{p}=0.12) .{ }^{32}$ Conversely, recent articles have found no difference in survival between the two groups, therefore stating prior PCI does not negatively impact survival. ${ }^{34} 35$

\section{In contrast to previous literature, we did not find a significant difference}

Although various studies have described survival outcomes, greater than 10-year survival rates have not yet been studied to determine the long-term survival. Our study aims report on survival up to 15 years after the CABG. Our results confirm with the later cluster of studies that found no significant difference in survival at 5, 10 and 15 years between the two groups. However, we acknowledge the smaller sample size of patients at 15 years. While prior PCI was not significantly associated with survival, Cox analysis revealed various patient 


\begin{tabular}{|c|c|c|c|c|}
\hline \multicolumn{2}{|l|}{ Variable (no missing) } & PCI, n=1090 & Non-PCl, $\mathrm{n}=10241$ & $P$ value \\
\hline \multicolumn{2}{|l|}{ Transfused blood used (2) } & $12.70 \%$ & $14.80 \%$ & 0.058 \\
\hline \multicolumn{2}{|l|}{ Units of blood used (1) } & $0(0,0)$ max eight units & $0(0,0)$ max 20 units & 0.046 \\
\hline \multicolumn{2}{|l|}{ Postoperative stroke (6) permanent } & $0.60 \%$ & $0.40 \%$ & \\
\hline & Transient & $<0.1 \%$ & $0.30 \%$ & \\
\hline & All together & $0.70 \%$ & $0.80 \%$ & 0.059 \\
\hline \multirow[t]{4}{*}{ Pulmonary complications (9845) } & Chest infection/other & $10.40 \%$ & $11.50 \%$ & 0.5 \\
\hline & Embolus & 0 & $<0.1 \%$ & \\
\hline & Reintubate & $2.30 \%$ & $1.70 \%$ & \\
\hline & All together & $12.70 \%$ & $13.20 \%$ & 0.67 \\
\hline \multirow[t]{3}{*}{ Gl complications (3) } & Ischaemic bowel/pancreatitis & $1.20 \%$ & $1.10 \%$ & \\
\hline & Peptic ulcer/Gl bleed & $0.40 \%$ & $0.50 \%$ & \\
\hline & All together & $1.60 \%$ & $1.50 \%$ & 0.9 \\
\hline \multicolumn{2}{|l|}{ Organ failure (3) } & $1.00 \%$ & $0.60 \%$ & 0.16 \\
\hline \multicolumn{2}{|l|}{ Hospital LOS (2) in days } & $6(5,8)$ max 187 days & $6(5,8) \max 204$ days & $<0.001$ \\
\hline Variable & Subvariable & PCI, n=1058 & Non-PCI, $n=1058$ & $P$ value \\
\hline \multicolumn{2}{|l|}{ Transfused blood used } & $12.60 \%$ & $14.70 \%$ & 0.18 \\
\hline \multicolumn{2}{|l|}{ Units of blood used } & $0(0,0)$ max 8 units & $0(0,0)$ max 8 units & 0.12 \\
\hline \multirow[t]{3}{*}{ Postoperative stroke } & Permanent & $0.38 \%$ & $0.57 \%$ & \\
\hline & Transient & $0.38 \%$ & $0.57 \%$ & \\
\hline & All together & $0.76 \%$ & $1.13 \%$ & 0.5 \\
\hline \multirow[t]{4}{*}{ Pulmonary complications } & Chest infection/other & $10.50 \%$ & $13.90 \%$ & \\
\hline & Embolus & 0 & $<0.1 \%$ & \\
\hline & Reintubate & $2.40 \%$ & $1.60 \%$ & \\
\hline & All together & $12.90 \%$ & $15.60 \%$ & 0.09 \\
\hline \multirow[t]{3}{*}{ Gl complications } & Ischaemic bowel/pancreatitis & $1.20 \%$ & $1.40 \%$ & \\
\hline & Peptic ulcer/Gl bleed & $0.38 \%$ & $0.28 \%$ & \\
\hline & All together & $1.60 \%$ & $1.70 \%$ & $>0.99$ \\
\hline \multicolumn{2}{|l|}{ Organ failure } & $0.90 \%$ & $0.80 \%$ & 0.81 \\
\hline \multicolumn{2}{|l|}{ Hospital LOS, in days } & 6(5 8) max 187 days & $6(5$ 8) max 62 days & 0.054 \\
\hline
\end{tabular}

Bold values within the $P$ value column indicate statistically significant values.

$\mathrm{Gl}$, gastrointestinal; LOS, length of stay; $\mathrm{PCl}$, percutaneous coronary intervention.

demographic and preoperative risk factors that were strongly associated with the hazard of death. Some factors must be interpreted with caution as the Cox model only considers all-cause mortality. For example, patients with functioning renal transplant have competing risks of death from infection and renal disease over cardiac reasons, thus in-depth analysis of cause of death is

Table 3 Comparison of postoperative mortality and survival

\begin{tabular}{|c|c|c|c|c|}
\hline & $\begin{array}{l}\mathrm{PCI} \\
\text { (matched) }\end{array}$ & $\begin{array}{l}\text { No PCI } \\
\text { (matched) }\end{array}$ & $\begin{array}{l}\mathrm{PCl} \\
\text { (all data) }\end{array}$ & $\begin{array}{l}\text { No PCI } \\
\text { (all data) }\end{array}$ \\
\hline$n$ & 1058 & 1058 & 1080 & 10242 \\
\hline No of deaths & $145(13.8 \%)$ & $253(24.0 \%)$ & $149(13.8 \%)$ & $941(9.2 \%)$ \\
\hline Mean survival (years) & $5.23(\mathrm{SD}=3.49)$ & $8.04(S D=4.75)$ & $5.33(\mathrm{SD}=3.52)$ & $8.12(S D=4.79)$ \\
\hline 30 days postoperative mortality & $1.4 \%$ & $1.5 \%$ & $1.5 \%$ & $1.2 \%$ \\
\hline 5 years survival & $87.9 \%$ & $90.8 \%$ & $88.2 \%$ & $89.8 \%$ \\
\hline 10 years survival & $74.6 \%$ & $76.5 \%$ & $75.1 \%$ & $76.8 \%$ \\
\hline 15 years survival & $64.7 \%$ & $64.4 \%$ & $64.7 \%$ & $59.2 \%$ \\
\hline
\end{tabular}

$\mathrm{PCl}$, percutaneous coronary intervention. 


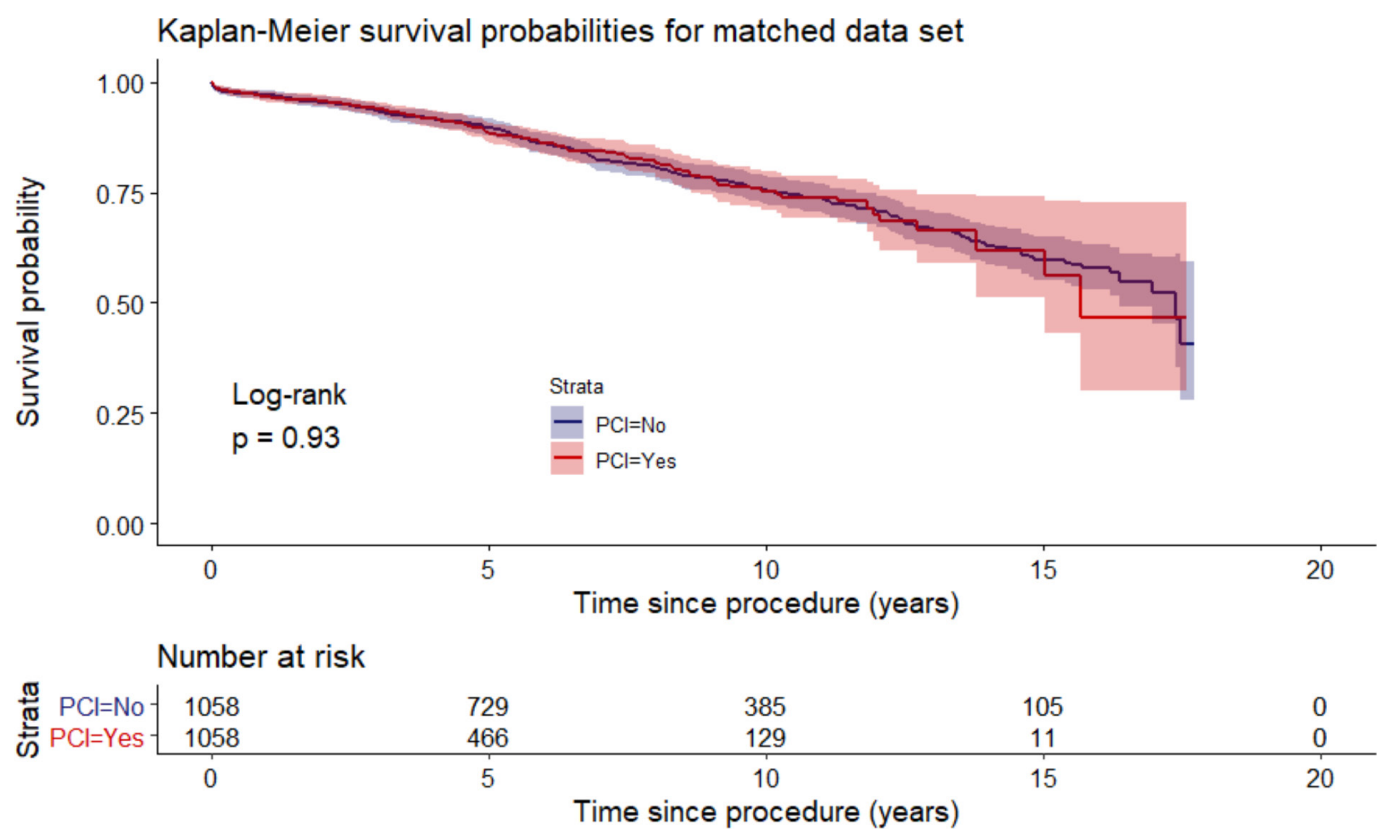

Figure 2 Kaplan-Meier plot of survival probabilities for $\mathrm{PCl}$ (red) and non- $\mathrm{PCl}$ (blue) groups in the matched set. There is no difference in survival between $\mathrm{PCl}$ and non- $\mathrm{PCl}$ groups here, graphically represented by the Kaplan-Meier curves sitting almost on top of each other. Log-rank test $\mathrm{p}=0.93$. $\mathrm{PCl}$, percutaneous coronary intervention.

necessary to make concrete statements regarding risk with CABG and transplant.

\section{Limitations}

This paper focused was on single-centre, retrospective and matched data. Due to anonymisation of patient data, we are not able to widen the scope of the paper to prove absolute associations of mortality between patient and the intraoperative covariates associated with CABG; this is limited due to lack of information regarding the competing risk of mortality, for example, patients with diabetes might be more likely to have reduced survival due to non-cardiac complications of diabetes rather than a sole cardiac cause. The retrospective design increases susceptibility to selection and observational bias.

Additionally, presence of extraneous variables not factored into the analysis can influence the small discrepancies in the results between the two groups. Our overall sample size was large, however, very few patients in the database had their CABG more than 15 years ago, thus minimising data on 15-year survival. As always,

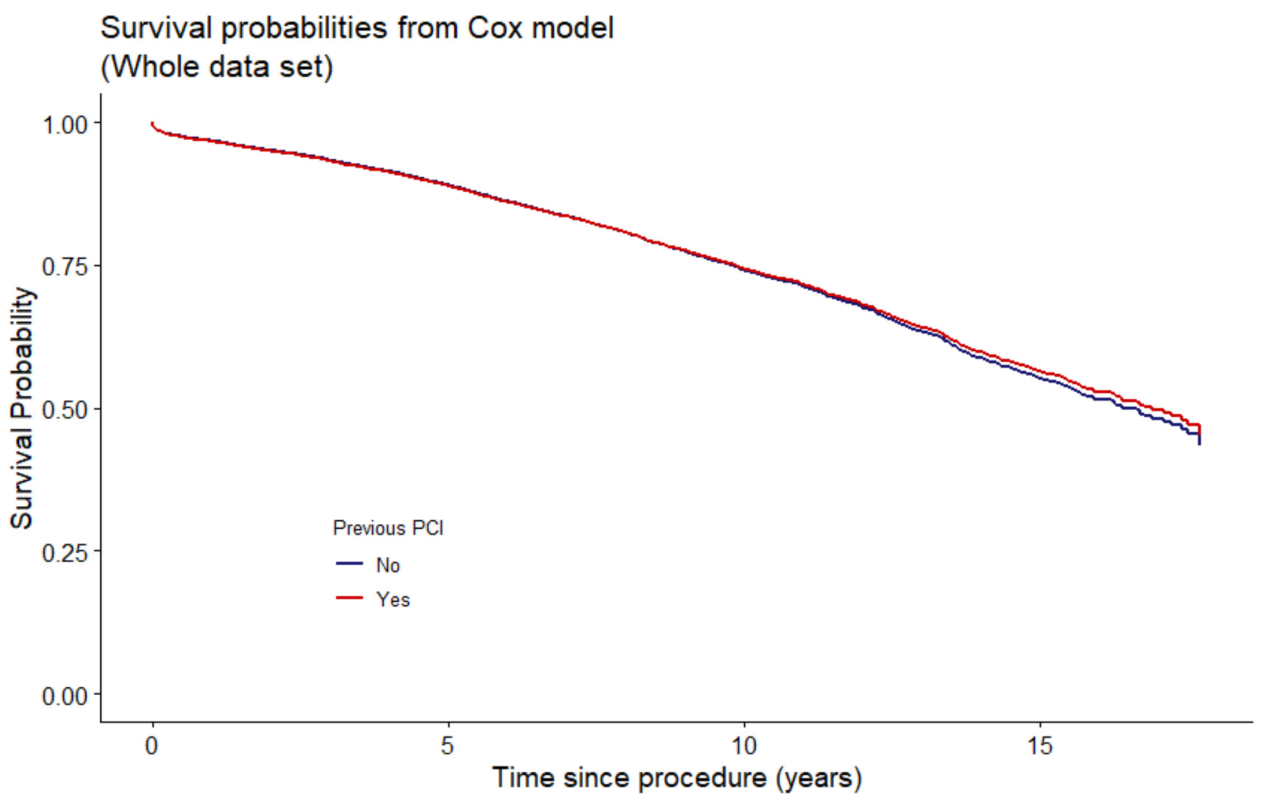

Figure 3 Adjusted survival curves calculated from the Cox proportional hazards model described in table 4. An average of the survival estimates for patients in each of the $\mathrm{PCl}$ groups is taken using the parameters of the Cox model. Again, we see no difference in survival between groups. PCl, percutaneous coronary intervention. 
Table 4 Covariate estimates produced by Cox pH model of survival, $n=6921$ (4410 observations not used due to missingness

\begin{tabular}{|c|c|c|c|c|}
\hline Covariate & & HR & $P$ value & $95 \% \mathrm{Cl}$ \\
\hline Previous PCI & Yes & 1.058 & 0.59 & (0.86 to 1.30 ) \\
\hline Age & & 1.063 & $<0.001$ & (1.05 to 1.07 ) \\
\hline Sex & Female & 0.886 & 0.044 & (0.79 to 1.00 ) \\
\hline Hypertension & Treated & 0.765 & 0.007 & (0.63 to 0.93 ) \\
\hline \multirow[t]{2}{*}{ Ejection fraction } & Fair & 1.191 & 0.005 & (1.05 to 1.35 ) \\
\hline & Poor & 1.968 & $<0.001$ & (1.54 to 2.51 ) \\
\hline \multirow[t]{3}{*}{ Angina status } & $\operatorname{ccs} 2$ & 0.892 & 0.11 & (0.78 to 1.02 ) \\
\hline & $\operatorname{ccs} 3$ & 0.943 & 0.43 & (0.82 to 1.09 ) \\
\hline & $\operatorname{ccs} 4$ & 0.887 & 0.17 & (0.75 to 1.05 ) \\
\hline \multirow[t]{3}{*}{ Dyspnoea status } & NYHA 2 & 1.024 & 0.72 & (0.90 to 1.16 ) \\
\hline & NYHA 3 & 1.302 & $<0.001$ & (1.14 to 1.49 ) \\
\hline & NYHA 4 & 1.093 & 0.47 & (0.86 to 1.39 ) \\
\hline \multirow[t]{2}{*}{ Previous MI } & One & 1.030 & 0.61 & (0.92 to 1.15$)$ \\
\hline & Two or more & 1.268 & 0.002 & (1.09 to 1.47 ) \\
\hline Diabetes (any) & Yes & 1.393 & $<0.001$ & (1.25 to 1.55$)$ \\
\hline \multirow[t]{2}{*}{ Smoking status } & Ex-smoker & 1.389 & $<0.001$ & (1.24 to 1.56$)$ \\
\hline & Current smoker & 1.726 & $<0.001$ & (1.44 to 2.06 ) \\
\hline \multirow[t]{3}{*}{ Renal failure } & Yes, no dialysis & 1.433 & 0.050 & (1.00 to 2.05 ) \\
\hline & Yes, dialysis & 3.434 & $<0.001$ & (2.01 to 5.87 ) \\
\hline & Transplant & 33.91 & $<0.001$ & (10.7 to 108) \\
\hline $\begin{array}{l}\text { History of pulmonary } \\
\text { disease }\end{array}$ & Yes & 1.198 & 0.009 & (1.05 to 1.37 ) \\
\hline $\begin{array}{l}\text { Extracardiac } \\
\text { arteriopathy }\end{array}$ & Yes & 1.378 & $<0.001$ & (1.21 to 1.56$)$ \\
\hline No of distal arteries & $(\log )$ & 0.854 & 0.037 & (0.74 to 0.99 ) \\
\hline Euroscore & & 1.098 & $<0.001$ & (1.06 to 1.13 ) \\
\hline Bypass time & & 1.002 & 0.067 & (1.00 to 1.00$)$ \\
\hline Clamp time & & 0.995 & 0.007 & (0.99 to 1.00 ) \\
\hline
\end{tabular}

CCS, Canadian Cardiovascular Society grading for angina pectoris; MI, myocardial infarction; $\mathrm{PCl}$, percutaneous coronary intervention.

though matching goes some way to imitating a properly randomised controlled trial, we also cannot know whether the decision to perform CABG was related to the knowledge of prior PCI at the time and thus inference should be made with the understanding of the assumption that it was not.

\section{What this study adds}

Regardless, this single-centre study has a large sample size, providing a smaller margin of error, with up to 15-year survival period. The range of statistical analysis demonstrates strong acceptance of the null hypothesis. Our results accept the studies that conclude the absence of disparity in long-term survival with prior PCI, adding more clarity to the currently conflicting literature. In addition, the results provide a foundation for future large-scale, prospective multicentre studies to confirm the effect on prior PCI and the association between patient and operative factors on mortality. Finally, the findings are also reassuring for patients who have had prior PCI, undergoing $\mathrm{CABG}$.

\section{CONCLUSION}

Overall, we found no difference in 5-year, 10-year and 15-year survival between patients undergoing CABG with or without prior PCI. Certain patient, preoperative and intraoperative risk factors were identified with high hazard of death which needs to be investigated further.

Contributors Planning of the study: PR, RT and MNB. Performance of the analyses: RT. Reporting of the work: PR, RT and MNB. Responsible for the overall content: PR.

Funding The authors have not declared a specific grant for this research from any funding agency in the public, commercial or not-for-profit sectors.

Competing interests None declared.

Patient consent for publication Not required.

Provenance and peer review Not commissioned; externally peer reviewed.

Data availability statement Data are available in a public, open access repository. All data relevant to the study are included in the article or uploaded as online supplemental information. No additional data are available.

Open access This is an open access article distributed in accordance with the Creative Commons Attribution Non Commercial (CC BY-NC 4.0) license, which permits others to distribute, remix, adapt, build upon this work non-commercially, and license their derivative works on different terms, provided the original work is properly cited, appropriate credit is given, any changes made indicated, and the use is non-commercial. See: http://creativecommons.org/licenses/by-nc/4.0/.

ORCID iDs

Pratik Rai http://orcid.org/0000-0001-8623-6695

Rebecca Taylor http://orcid.org/0000-0001-6699-3867

\section{REFERENCES}

1 Foundation BH. BHF Factsheets - UK British Heart Foundation, 2018. Available: https://www.bhf.org.uk/what-we-do/our-research/ heart- [Accessed 11 2018].

2 Otsuka F, Yahagi K, Sakakura K, et al. Why is the mammary artery so special and what protects it from atherosclerosis? Ann Cardiothorac Surg 2013;2:519-26

3 Sabik JF, Lytle BW, Blackstone EH, et al. Comparison of saphenous vein and internal thoracic artery graft patency by coronary system. Ann Thorac Surg 2005;79:544-51.

4 Singh RN, Sosa JA, Green GE. Internal mammary artery versus saphenous vein graft. Comparative performance in patients with combined revascularisation. Br Heart J 1983;50:48-58.

5 Hawkes AL, Nowak M, Bidstrup B, et al. Outcomes of coronary artery bypass graft surgery. Vasc Health Risk Manag 2006;2:477-84.

6 (NHS) NHS. Coronary artery bypass graft: NHS, 2018. Available: https://www.nhs.uk/conditions/coronary-artery-bypass-graft-cabg/ [Accessed 07 Nov 2018].

7 Diodato M, Chedrawy EG. Coronary artery bypass graft surgery: the past, present, and future of myocardial revascularisation. Surg Res Pract 2014;2014:1-6.

8 Rull G. Percutaneous coronary intervention. Available: https:// patient.info/doctor/percutaneous-coronary- intervention\#nav-2 [Accessed 23 Sep 2016].

9 Percutaneous coronary intervention ( $\mathrm{PCl}$ or angioplasty with stent): heart and stroke Foundation of Canada. Available: https://www. heartandstroke.ca/heart/treatments/surgery-and-other- procedures/ percutaneous-coronary-intervention

10 Buccheri D, Piraino D, Andolina G, et al. Understanding and managing in-stent restenosis: a review of clinical data, from pathogenesis to treatment. J Thorac Dis 2016;8:E1150-62.

11 Sudheendra D. Stent Medlineplus, 2018. Available: https:// medlineplus.gov/ency/article/002303.htm [Accessed 6 Oct 2018].

12 Kipshidze N, Dangas G, Tsapenko M, et al. Role of the endothelium in modulating neointimal formation: vasculoprotective approaches to attenuate restenosis after percutaneous coronary interventions. J Am Coll Cardiol 2004;44:733-9. 
13 Stolker Joshua M, Cohen David J, Kennedy Kevin F, et al. Repeat revascularization after contemporary percutaneous coronary intervention. Circulation: Cardiovascular Interventions 2012;5:772-82.

14 Serruys PW, Ong ATL, van Herwerden LA, et al. Five-Year outcomes after coronary stenting versus bypass surgery for the treatment of multivessel disease. J Am Coll Cardiol 2005;46:575-81.

15 Spadaccio C, Benedetto U. Coronary artery bypass grafting (CABG) vs. percutaneous coronary intervention $(\mathrm{PCI})$ in the treatment of multivessel coronary disease: quo vadis? -a review of the evidences on coronary artery disease. Ann Cardiothorac Surg 2018;7:506-15.

16 Deb S, Wijeysundera HC, DT K, et al. Coronary artery bypass graft surgery vs percutaneous interventions in coronary revascularization: a systematic ReviewCABG surgery vs $\mathrm{PCl}$ in coronary

RevascularizationCABG surgery vs $\mathrm{PCl}$ in coronary revascularization. JAMA 2013;310:2086-95.

17 Herbison P, Wong C-K. Has the difference in mortality between percutaneous coronary intervention and coronary artery bypass grafting in people with heart disease and diabetes changed over the years? A systematic review and meta-regression. BMJ Open 2015;5:e010055.

18 Abdallah MS, Wang K, Magnuson EA, et al. Quality of life after PCl vs CABG among patients with diabetes and multivessel coronary artery disease: a randomized clinical trial. JAMA 2013;310:1581-90.

19 Parasca CA, Head SJ, Milojevic M, et al. Incidence, Characteristics, Predictors, and Outcomes of Repeat Revascularization After Percutaneous Coronary Intervention and Coronary Artery Bypass Grafting: The SYNTAX Trial at 5 Years. JACC Cardiovasc Interv 2016;9:2493-507.

20 Yap C-H, Yan BP, Akowuah E, et al. Does prior percutaneous coronary intervention adversely affect early and mid-term survival after coronary artery surgery? JACC Cardiovasc Interv 2009;2:758-64.

21 Massoudy P, Thielmann M, Lehmann N, et al. Impact of prior percutaneous coronary intervention on the outcome of coronary artery bypass surgery: a multicenter analysis. J Thorac Cardiovasc Surg 2009;137:840-5.

22 Mehta GS, LaPar DJ, Bhamidipati CM, et al. Previous percutaneous coronary intervention increases morbidity after coronary artery bypass grafting. Surgery 2012;152:5-11.

23 O'Neal WT, Efird JT, Anderson CA, et al. The impact of prior percutaneous coronary intervention on long-term survival after coronary artery bypass grafting. Heart, Lung and Circulation 2013;22:940-5.

24 NICOR. National Institute for cardiovascular outcomes research, 2019. Available: https://www.nicor.org.uk/about-nicor/

25 R Core Team. R: a language and environment for statistical computing. Vienna, Austria: R Foundation for Statistical Computing, 2019. https://www.R-project.org/

26 Daniel E, Elizabeth A. Stuart (2011). Matchlt: nonparametric preprocessing for parametric causal inference. Journal of Statistical Software;42:1-28.

27 Mokadam NA, Melford RE, Maynard C, et al. Prevalence and procedural outcomes of percutaneous coronary intervention and coronary artery bypass grafting in patients with diabetes and multivessel coronary artery disease. J Card Surg 2011;26:1-8.

28 Stone GW. Multivessel PCl on its 40th anniversary: finally a match for CABG? Eur Heart J 2017:38:3135-8.

29 Escaned J, Collet C, Ryan N, et al. Clinical outcomes of state-of-theart percutaneous coronary revascularization in patients with de novo three vessel disease: 1-year results of the SYNTAX II study. Eur Heart J 2017;38:3124-34.

30 Nyström T, Sartipy U, Franzén S, et al. PCI Versus CABG in Patients With Type 1 Diabetes and Multivessel Disease. J Am Coll Cardiol 2017;70:1441-51.

31 Brancati MF, Burzotta F, Trani C, et al. Coronary stents and vascular response to implantation: literature review. Pragmat Obs Res 2017:8:137-48

32 Eifert S, Mair H, Boulesteix A-L, et al. Mid-Term outcomes of patients with $\mathrm{PCl}$ prior to $\mathrm{CABG}$ in comparison to patients with primary CABG. Vasc Health Risk Manag 2010;6:495-501.

33 Altarabsheh SE, Deo SV, Hang D, et al. Coronary artery bypass grafting after percutaneous intervention has higher early mortality: a meta-analysis. Ann Thorac Surg 2015;99:2046-52.

34 Luthra S, Leiva Juárez MM, Senanayake E, et al. Percutaneous Intervention Before Coronary Artery Bypass Surgery Does Not Unfavorably Impact Survival: A Single-Center PropensityMatched Analysis. Ann Thorac Surg 2016;102:1911-8.

35 Fukui T, Tanaka S, Takanashi S. Previous coronary stents do not increase early and long-term adverse outcomes in patients undergoing off-pump coronary artery bypass grafting: a propensity-matched comparison. J Thorac Cardiovasc Surg 2014;148:1843-9. 